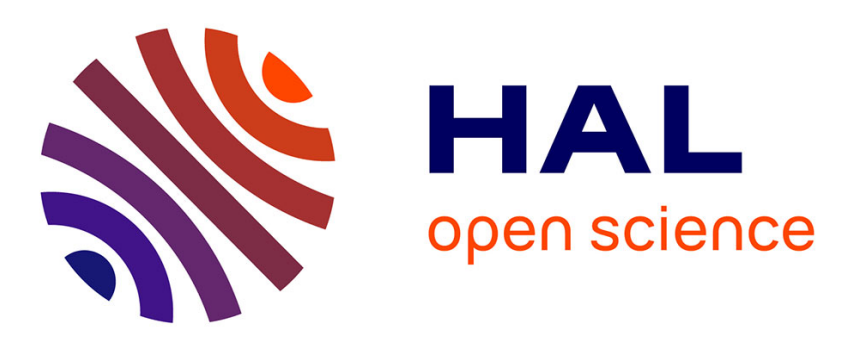

\title{
MIOR: an individual-based model for simulating the spatial patterns of soil organic matter microbial decomposition
}

Dominique Masse, Christophe Cambier, Alain Brauman, Saïdou Sall, Komi Assigbetse, Jean-Luc Chotte

\section{To cite this version:}

Dominique Masse, Christophe Cambier, Alain Brauman, Saïdou Sall, Komi Assigbetse, et al.. MIOR : an individual-based model for simulating the spatial patterns of soil organic matter microbial decomposition. European Journal of Soil Science, 2007, 58 (5), pp.1127-1135. 10.1111/j.13652389.2007.00900.x . ird-00190929

\section{HAL Id: ird-00190929 \\ https://hal.ird.fr/ird-00190929}

Submitted on 23 Nov 2007

HAL is a multi-disciplinary open access archive for the deposit and dissemination of scientific research documents, whether they are published or not. The documents may come from teaching and research institutions in France or abroad, or from public or private research centers.
L'archive ouverte pluridisciplinaire HAL, est destinée au dépôt et à la diffusion de documents scientifiques de niveau recherche, publiés ou non, émanant des établissements d'enseignement et de recherche français ou étrangers, des laboratoires publics ou privés. 
MIOR: an individual-based model for simulating the spatial patterns of soil organic matter microbial decomposition

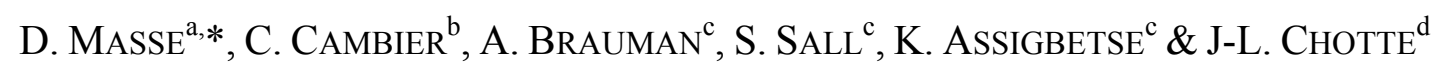
${ }^{\mathrm{a}}$ IRD, UR179 SeqBio, BP182 01 Ouagadougou, Burkina Faso, ${ }^{\mathrm{b}}$ IRD / Laboratoire Informatique Paris 6, UR Geodes, BP1386, Dakar, Senegal, ' IRD, UR179 SeqBio, BP1386 Dakar, Senegal, and IRD, UR179 SeqBio, BP 64501, 34394 Montpellier Cedex 5, France Correspondence: D. MASSE. E-mail: dominique.masse@ird.fr, * current adress: IRD/LRI, BP434 101 Antananarivo, Madagascar Received 19 April 2005; revised version accepted 


\section{Summary}

An individual-based model, called MIOR, was designed to assess hypotheses on the effect of the spatial distribution of organic matter and microbial decomposers on soil carbon and nitrogen dynamics. Two main types of object were defined to represent the decomposers and the soil organic substrates. All these objects were positioned in a 3D space. The exchange of carbon and nitrogen between these various entities was simulated. Two scenarios were tested according to the degrees of clustering of organic matter and of microorganisms. The results of simulations highlighted the effect of the ratio of accessible organic carbon to microbial carbon on the dynamics of microbial biomass and $\mathrm{CO}_{2}$ release. This ratio was determined by the number of contacts between one object representing the microbial decomposers and the surrounding objects representing the organic substrates.

\section{Résumé}

\section{MIOR: modèle individu-centré de simulation de la distribution spatiale des} processus microbiens de la décomposition des matières organiques dans les sols.

Un modèle individu-centré, appelé MIOR, a été conçu pour tester les hypothèses concernant les effets de la distribution spatiale des matières organiques et des micro-décomposeurs dans les sols sur la dynamique du carbone et de l'azote minéral. Deux principaux types d'objets ont été définis représentant les microorganismes décomposeurs et les substrats organiques. Ces objets sont positionnés dans une espace à trois dimensions. Les échanges de carbone et d'azote entre ces deux entités sont simulés. Deux scénarios sont testés selon des niveaux d'agrégation des microorganismes et celui des matières organiques. Les résultats des simulations mettent en avant l'importance de la quantité de carbone organique accessible par 
unité de carbone microbien sur la dynamique de la biomasse microbienne et du CO2 dégagé.

Cette quantité est déterminée par le nombre de contacts entre un objet représentant des microdécomposeurs et des objets qui l'entourent représentant les substrats organiques. 


\section{Introduction}

Soil is a complex system. Many biological processes take place in soil and determine functions that provide various services within ecosystems: turn-over of organic matter, symbiotic and non-symbiotic atmospheric nitrogen fixation, denitrification, aggregation, etc. (Chenu \& Stotzky, 2002; Young \& Crawford, 2004). Soil is a medium with solids, liquids and gases in which the mineral and organic particles form differently-sized aggregates that delimit pores (Tisdall \& Oades, 1982; Feller \& Beare, 1997; Six et al., 2000; Six et al., 2004). This organization creates micro-environments that are suited to microbial activity to varying extents (Chotte et al., 1997). Some studies have investigated the spatial distribution of microbes in soil. Nunan et al. (2001) described the spatial distribution of bacterial cells in an undisturbed soil by means of large-scale imaging of thin sections. They confirmed the patchiness of bacterial distribution as a result of cell growth mechanisms and of environmental constraints. Grundmann \& Debouzie (2000) observed the micro-scale distribution of the $\mathrm{NH}_{4}{ }^{+}$and $\mathrm{NO}_{2}{ }^{-}$oxidizer community in a bulk soil at a micro-millimetre scale. Recent studies have pointed out the importance of taking into consideration the distribution within the soil matrix of microbial activity hot spots (Gaillard et al., 2003; Vieublé-Gonod et al., 2003). Young \& Crawford (2004) emphasized the importance of 3D dynamic modeling to study the structural organization of soil and that has to be associated with spatial representation of the biological activity in soil (Ettema \& Wardle, 2002).

Soil, therefore, must be considered not as a uniform space but as a changing pattern of "spots" characterized by microbial activity of variable intensity. The question of the extent to which this heterogeneous space affects the microbial processes involved in the various services provided by the soil to the ecosystems is fundamental.

Several studies have shown the effect of the size of the organic residue on the intensity of mineralization. Among the various factors such as biochemical composition, the surface of 
the contact area between this residue and the organo-mineral matrix of the soil is considered as one of the main determinants (Angers \& Recous, 1997; Bending \& Turner, 1999). Wachinger et al. (2000) highlighted the relation between $\mathrm{CH}_{4}$ release by methanogenic microbes and micro-scale hot spots of organic substrate in soil cores. Although the patterns of spatial distribution of the microorganisms in the soils were described, no experiment has provided conclusive information about the effect of spatial distribution of microorganisms on the processes of decomposition of organic substrates. This lack of information can be explained partly by the difficulty, or even impossibility, of manipulating these microorganisms and controlling their distribution in the soil matrix.

Mathematical models are useful methodological tools for designing and simulating complex processes such as SOM decomposition (Peck, 2004). In most models used to simulate soil organic matter decomposition i) soil is considered as a homogenous medium, ii) organic resources are represented as a series of discrete pools related to each other by first order kinetic functions, and iii) microbial decomposers are represented as a single pool, homogeneously distributed in the soil (McGill, 1996). Although these models have been widely used, several authors have pointed out their limits (Christensen, 1996). Garnier et al. (2003) improved the prediction of $\mathrm{C}$ and $\mathrm{N}$ mineralization of added straw residues by adding a function for the colonization by decomposers of the substrate to the original model CANTIS. Several models enhanced the representation of the microbial activity. Blagodatsky \& Richter (1998) proposed a model to simulate nitrogen turnover where the microbial community is described according to its physiological state e.g., active versus dormant. The CANTIS model distinguishes autochthonous and zymogenous biomasses (Garnier et al., 2003). The SOMKO model was based on the trophic relationships between microorganisms and organic substrates (Gignoux et al., 2001). 
Individual-based models or multi-agent systems have been used in many social and life science fields and more recently for environmental applications (Bousquet \& Le Page, 2004). This approach offers substantial advantages for ecological modeling such as the recognition of the distinct behavior of individuals in a spatially fluctuating environment (Ginot et al., 2002). Individual-based models (IBM) and multi-agents systems (MAS) allow levels of heterogeneity, i.e., microorganisms and organic substrates, and their distribution in a spatial environment, to be taken into consideration. So far as we are aware, only one IBM has been proposed in microbiology. This simulated the growth of bacteria cultured in a liquid medium (Kreft et al., 1998).

This article proposes an individual-based modeling approach (the MIOR model) to study microbial process of soil organic matter mineralization. For this first attempt, the soil was reduced to a virtual assemblage of aggregates of microorganisms and organic substrates. For this study, we assumed that exchanges of carbon and nitrogen between these two entities, e.g. the micro-decomposers and the organic resources, are effective only when they are in contact. This article describes the model and looks at whether the spatial distribution of microorganisms and/or organic resources has an impact on simulated values. Two scenarios are compared (i.e. the degree of clustering of microorganisms and of the organic resources). The results and limits of the model are then discussed.

\section{Materials and methods}

\section{The MIOR model}

\section{Model description}

An individual-based model, or a multi-agent system, comprises (i) an environment that is usually a space, (ii) a set of objects situated in this environment, (iii) a set of agents, which are specific objects that represent the active entities in the system, (iv) a set of relations that link 
objects (and therefore agents) together and (v) a set of operations that make it possible for the agents to perceive, produce, transform and manipulate objects (Bousquet \& Le Page, 2004).

In this study, the bulk soil was considered as a volume with two sets of objects (Figure 1):

1) Microorganisms, referred to as MetaMior $(M M)$,

2) Organic substrates, referred to as OMsphere $(O M)$.

\section{The MetaMior object}

Since (i) the density of the soil microorganisms is too large (between $10^{6}$ to $10^{9}$ cells g $^{-1}$ of soil) (Paul \& Clark, 1996) to allow a computer representation of each cell, and (ii) a microbial cell is unlikely to be found as a single cell in soils, a MetaMior ( $M M)$ corresponds to an aggregate of microorganisms. A MetaMior is characterized by its carbon content, $M M$ $\mathrm{C}_{\text {content }}$, and its nitrogen content $\left(M M-\mathrm{N}_{\text {content }}\right)$ which is determined by the C-to-N ratio of microorganisms $(C N)$. Two physiological states are considered:

1) A dormant state, where no substrate is consumed, with cells in a resting state,

2) An active state, where microbial cells consume energy and nutrients to fulfil their basal metabolism and thereafter allow their growth.

Cell metabolism converts substrate into microbial biomass and metabolites $\left(\mathrm{CO}_{2}\right.$, inorganic N) via the equation described in the SOMKO model (Gignoux et al., 2001). A dormant MetaMior becomes active when its maintenance needs are fulfilled by the presence of organic $\mathrm{C}$ as a source of energy. Maintenance energy encompasses all energy expenditure not directly contributing to growth. It corresponds to the respiration rate, $R R\left(\right.$ time $\left.^{-1}\right)$ which is considered to be constant with time. It also determines the $\mathrm{CO}_{2}$ production. When the source of energy (organic $\mathrm{C}$ from the OMspere) is not sufficient to support microbial growth, a fraction of the biomass, equal to the carbon deficit, becomes dormant. On the other hand, when the maintenance needs are satisfied, the active part of a MetaMior is able to grow. The 
MetaMior growth is limited by a potential growth rate, GR (time $\left.{ }^{-1}\right)$ and depends on the balance of carbon and nitrogen availability.

At each time step of the simulation, the MetaMior's needs for carbon $\left(M M-\mathrm{C}_{\text {needs }}\right)$ and nitrogen ( $\left.M M-\mathrm{N}_{\text {needs }}\right)$ are evaluated with the following equations:

$$
\begin{aligned}
& M M-\mathrm{C}_{\text {needs }}=R R \times M M-\mathrm{C}_{\text {content }}+G R \times M M-\mathrm{C}_{\text {content }}(1), \\
& M M-\mathrm{N}_{\text {needs }}=C N \times G R \times M M-\mathrm{N}_{\text {content }}(2) .
\end{aligned}
$$

\section{The OMsphere object}

An OMsphere object $(O M)$ that represent the organic substrate is split into several organic pools. Each pool, I, is characterized by a C-to-N ratio $\left(C N_{\mathrm{OMi}}\right)$ and a decomposition rate (i.e., $\left.k_{\mathrm{i}}\right)$. Available carbon and nitrogen for the MetaMior is calculated at each time step with the following equations:

$$
\begin{aligned}
& O M-\mathrm{C}_{\text {available }}=\sum k_{\mathrm{i}} \mathrm{C}_{\mathrm{i}}(3), \\
& O M-\mathrm{N}_{\text {available }}=\sum k_{\mathrm{i}} \mathrm{C}_{\mathrm{i}} C N_{\mathrm{OMi}}(4),
\end{aligned}
$$

where $\mathrm{C}_{\mathrm{i}}, k_{\mathrm{i}}$ and $C N_{\mathrm{OMi}}$ are respectively the $\mathrm{C}$ content, the decomposition rate and the $\mathrm{C}$-to$\mathrm{N}$ ratio of the pool, $\mathrm{I}$, of an organic substrate entity.

\section{The environment}

MetaMiors $(M M s)$ and OMspheres $(O M s)$ are spheres randomly distributed in a continuous 3D space (Figure 1). One important attribute of a MetaMior agent is its neighbouring collections of $O M S$ which determine the amount of $\mathrm{C}$ and $\mathrm{N}$ available for it. Two objects are neighbors if the distance between their centres is no more than the sum of the radii of their respective spheres. The radius of the sphere representing one object is calculated from its volume which is defined as the total volume occupied in the whole environment by the whole collection of these objects divided by the number of these objects.

\section{Running the model}




\section{Initialization of the parameters of each object}

Each $O M$ object was divided into four different pools very similar to those proposed in the literature (Ågren \& Bosatta, 1996; Gignoux et al., 2001): i.e., cellulose, hemicellulose, lignin and simple molecules (e.g., carbohydrates or amino acids). For each pool, the decomposition rate and the C-to-N ratio were those given by Minderman (1968) and Trinsoutrot et al. (2000) (Table 1).

Neither the number of MetaMior or $O M$ objects nor their distribution within the whole volume of their environment is precisely documented. Nevertheless, Grundmann et al. (2001) showed that nitrifier soil microbial communities occurred in patches that occupy at least 5.5\% of the volume of the soil matrix. The relative volumes $(R V)$ to the whole volume for both $O M$ and $M M$ entities were fixed at $10 \%$. The maximum number of objects that could be simulated in a reasonable time-scale was $500 O M$ and $500 M M$ objects. The sum of the carbon content of the each MetaMior $\left(M M-\mathrm{C}_{\text {content }}\right)$ represented $1 \%$ of the sum of the $O M$ carbon content. It is referred to as the total Microbial Biomass $\mathrm{C}$ content $(M B-\mathrm{C})$.

\section{Distribution of the different objects}

The sets of objects (e.g. $M M, O M$ ) were randomly distributed in a 3D environment (Figure 1). Their respective coordinate and the collections of neighboring objects were defined for each object.

\section{The process}

The simulation starts by initializing every object and the whole environment. The exchange of carbon and nitrogen between objects is then calculated using the MetaMior list. For each MetaMior, the active part is considered before the dormant part. Into this process, the growth of a MetaMior agent is first limited by carbon availability and then by nitrogen availability (Gignoux et al., 2001). The rates of growth and $\mathrm{CO}_{2}$ respiration depend on the equilibrium 
between the amount of accessible $\mathrm{C}$ and $\mathrm{N}\left(O M-\mathrm{C}_{\text {accessible, }} O M-\mathrm{N}_{\text {accessible }}\right)$, the amount of available $\mathrm{C}$ and $\mathrm{N}\left(O M-\mathrm{C}_{\text {available, }} O M-\mathrm{N}_{\text {available }}\right)$ from $O M s$ in contact with each MetaMior and the individual needs of each MetaMior for $\mathrm{C}$ and $\mathrm{N}\left(M M-\mathrm{C}_{\text {needs }}, M M-\mathrm{C}_{\text {needs }}\right)$. In this first version of MIOR, only one contact with an $O M$ is sufficient for a MetaMior to be able to use the total available carbon and nitrogen resources of this $O M$. Moreover, according to the sequential properties of the computer program, the processes of carbon and nitrogen exchange are sequentially applied to each MetaMior. However, the order of each object in the list of MetaMior, as of $O M$, is randomly modified at each time-step.

\section{Computer programming}

The program was written in 'Smalltalk', an object-oriented language, using 'Squeak' freeware (www.squeak.com).

\section{Experimental simulations: effect of MM or OM clustering}

This paper compares the impact of MetaMior clustering or OMsphere clustering on simulated values of the carbon content of the MetaMior objects $\left(M M-\mathrm{C}_{\text {content }}\right)$, and of the $\mathrm{C}-\mathrm{CO}_{2}$ respiration magnitude over time (500 time steps). Two different scenarios, i.e. the degree of clustering of the MetaMior objects (scenario 1) and the degree of clustering of $O M$ objects (scenario 2) were tested. Two cases were considered for each scenario: a small degree of clustering (denoted as $S-M M$ and $S$-OM respectively for each scenario), a large degree of clustering (denoted as $L-M M$ and $L-O M$ respectively for each scenario). Figure 2 illustrates the different levels of clustering. The control case (no clustering) simulated $500 \mathrm{OM}$ and 500 $M M$ objects (Table 1).

The total carbon and the relative amount of space occupied by the OMsphere and the MetaMior sets was the same for each scenario. Reducing the number of objects (OM and $M M$ ) increased their volume (and their radius) (Figure 2). 
Results of the simulations analysis

The distribution in space of the sets of objects was initialized randomly. Each simulation was, therefore, unique even if the same set of parameters was used. Each scenario was simulated five times and the standard errors of the output variables were calculated.

\section{Results}

\section{Initial state}

When the model is initialized, the quantity of carbon accessible for each MetaMior is represented by the ratio: $O M-\mathrm{C}_{\text {accessible }} / M M-\mathrm{C}_{\text {content }}$ (Figure 3). The simulation gives discrete values from 0 to 2000 for this ratio. Zero indicates that no organic resources are accessible to a MetaMior due to the absence of contact between this MetaMior and any adjacent OMspheres. The number of MetaMior (as a percentage of the total number) for each of these values can be counted. The histograms in Figure 3 show the differences between the scenarios tested. For scenario 1 (Figure 3A), the increase in the degree of clustering of the microbial consumers (Control, $S-M M, L-M M$ ) results in

1) a decrease in the number of MetaMior without resources (Figure $3 \mathrm{~A}$ ) from $49 \%$ for the control to $17 \%$ of the total number of MetaMior for the large degree of clustering $(L-M M)$.

2) an increase in the number of MetaMior with access to small amounts of $\mathrm{C}(O M$ $\left.\mathrm{C}_{\text {accessible: }}: M M-\mathrm{C}_{\text {content }}<100\right)$.

Contrary to scenario 1 (degree of clustering of MetaMior), the increase in the degree of clustering of the organic resource (Control, $S-O M, L-O M$ ) in scenario 2 causes an increase in the number of microbial consumers without resources (Figure 3B) and a greater proportion of microbial consumers with access to very large organic resources $\left(O M-\mathrm{C}_{\text {accessible }}: M M-\mathrm{C}_{\text {content }}\right.$ $>400)$. 
In the model, the ratio $O M-\mathrm{C}_{\text {accessible }}: M M-\mathrm{C}_{\text {content }}$ determines the dynamics of each microbial consumer $(M M)$. Figure 4 shows the simulation of the change in a MetaMior in relation to the amount of $\mathrm{C}$ that is accessible to it. The lack of organic resources $(O M-$ $\mathrm{C}_{\text {accessible }}: M M-\mathrm{C}_{\text {content }}=0$ ) naturally decreases $M M-\mathrm{C}_{\text {content }}$ by mortality after the first simulation time step. The increase in accessible resources produces an increase in $M M-\mathrm{C}_{\text {content }}$ which can reach values up to 35 times the initial value $\left(O M-\mathrm{C}_{\mathrm{accessible}}: M M-\mathrm{C}_{\text {content }}=1600\right)$. The overall dynamics of the total microbial biomass $(M B-C)$ depends on the distribution frequency of the various MetaMior across the various categories.

\section{Output variables}

For each time step, the model calculates the amount of carbon in the $M B-\mathrm{C}$ as well as the amount of $\mathrm{CO}_{2}-\mathrm{C}$ respired. Figures 5 and 6 show how these values change over 500 time steps. The variation in output for the different random realizations of the simulations is illustrated. The greatest standard errors are noticed for the greatest degree of clustering of $O M$ (scenario 2).

There are three successive phases in the total biomass change for each scenario:

1) a period of decrease,

2) a period of increase,

3) another period of decrease.

The cases and scenarios differ mainly in the duration of these phases. For scenario 1, which compares the different degrees of clustering of the MetaMior, the first two phases (increase followed by decrease) are shorter when there is an increase in the degree of clustering (Figure 5A). This is particularly clear for a large degree of clustering $(L-M M)$ where there is no initial decrease phase. The increase in the degree of clustering of MetaMior also reduces the maximum total biomass attained with respect to that measured in the control. 
For scenario 2, the greater the degree of clustering of the organic resources, the longer the first two phases compared with the control processing (Figure 5B). The lengthening of these periods implies greater variation in the total biomass value of the MetaMior. The maximum value is attained for the greatest degree of clustering of the OMsphere object $(L-O M)$.

For $\mathrm{CO}_{2}-\mathrm{C}$ production, the curves indicate less mineralization at the end of the number of steps simulated in scenario 1 for $S-M M$ and $L-M M$ processing than for the control (Figure $6 \mathrm{~A})$. On the contrary, there is greater mineralization for $S-O M$ and $L-O M$ processing in scenario 2. However, for both scenarios, for up to a third of the simulation time the effects of the degree of clustering on the amounts of $\mathrm{CO}_{2}$ respired appear to be inverted. For example, where the degree of clustering of $O M$ objects is increased, the amount of $\mathrm{CO}_{2}$ respired during this initial period is greater for the control than for the other cases (Figure 6B).

\section{Discussion}

Our theoretical work shows that the organic matter mineralization is modified when the spatial distribution of organic matter or microorganisms changes. The MIOR model used to simulate exchanges of carbon and nitrogen between entities that represent microorganisms and organic substrates indicates that the change in size and number of these objects disrupts the dynamics of the microbial biomass and the amount of $\mathrm{CO}_{2}$ respired.

The overall dynamics of the simulated system (OMsphere + MetaMior) are the sum of each entity. The individual dynamics of the aggregated microorganisms (MetaMior) in the model depend on the number of contacts with the organic matter entities (OMsphere). This number determines the amount of carbon available to maintain their basic metabolism and then their growth needs. According to the simulation results, the dynamics of the total microbial biomass, $M B-\mathrm{C}$, and mineralization of the $O M$ s depend on the number of MetaMior without any carbon resources. In the MIOR model, as these microorganisms do not have access to energy resources, they show negative growth. When organic matter is added, the 
smaller the proportion of organisms with access to this resource, the more the total microbial community will be dominated by the negative growth of the microorganisms without resources.

In laboratory or field experiments that add organic matter to a soil, it is quite conceivable that only a part of the microbial community has access to the organic substrates added. One single application cannot fill all the soil pores whether it is soluble or solid, whole or ground, applied to the surface or dug in. Equally, the microbial community in the soil may remain inactive either owing to local conditions that inhibit its development (anoxia, acidity, water stress, etc.) or because it is located in very stable micro-structures protected from the external environment. Several studies have demonstrated that micro-structures, such as $2-50 \mu \mathrm{m}$ micro-aggregates, protect soil microorganisms from desiccation or chemical stress such as mercury spiking (Vargas \& Hattori, 1986; Ranjard et al., 2000). Under such conditions, soil microorganisms are unaffected by organic inputs, or decline. However, several addition of organic matter or any disruption of the soil may, just by chance or by changing environmental conditions, increase the probability of that microorganisms will encounter organic resources, as described by the dynamic aggregate conceptual model used by Six et al. (2000). The MIOR model should, therefore, be modified to give a less static representation of the relationship between microbial and organic entities.

The analysis of scenario 1 (degree of clustering of MetaMior) indicates that, with the same resource distribution, a concentration of microbial activity in limited areas limits the mineralization of the organic resources in the long term. Although this concentration of microbial activity allows each microorganism hot spot to access carbon and nitrogen, it implies also a reduction in the ratio between the microbial biomass and the organic resources, thus limiting the growth of the microorganisms. However, over the short simulation times that we used, the differences in mineralization appear to be insignificant when the microbes are 
more and more concentrated into hot spots. These simulation results indicate that carbon mineralization would also depend on the size of the hot spots of microbial activity. In a study that described these hot spots in a Scottish arable field soil, Nunan et al. (2002) showed that the surface horizon (Ap) is characterized by smaller hot spots than those in the zones of activity observed in the adjacent horizon (Bt). It would be interesting to confirm the hypothesis raised by the results from our simulations, by comparing the mineralization processes after the addition of organic matter to undisturbed samples taken from these two horizons.

The analysis of scenario 2 (degree of clustering of OMsphere) indicates that for the same distribution of microorganisms, the increase in size and density of the organic substrates accentuates the extreme values of microbial biomass as well as 1) the mineralization of the organic matter and 2) the variability between repeated scenarios. In the MIOR model, the reduction in the number of OMsphere objects together with the increase in their size implies a reduction in the number of MetaMior with access to a resource, which explains an initial decrease in $M B-C$. However, the limited number of MetaMior which have access to these resources have a larger amount of carbon available which allows better growth, which in turn leads to a faster mineralization during the second phase. Moreover, in this scenario 2 , the number of MetaMior without access to an $O M$ resource and the ratio of organic carbon resources by microbial carbon are more variable between repeated simulations than in the case of scenario 1 (degree of clustering of MetaMior, data not shown), that explain the greatest standard errors of output values particularly for the scenario with the high degree of $O M$ clustering scenario. From an experimental study, Bending \& Turner (1999) showed that the size of particles of vegetal residues incorporated into the soil affects microbial activity $\left(\mathrm{CO}_{2}\right.$ release and microbial biomass) in interaction with the biochemical quality of this organic residue. The experimental values obtained by these authors are in line with the 
simulations produced by the MIOR model: the amount of $\mathrm{CO}_{2}$ released and the microbial biomass are greater in the presence of large organic residues $\left(0.2\right.$ to $\left.4 \mathrm{~cm}^{2}\right)$. Angers \& Recous (1997) incubated wheat straw with soils for 100 days and reached the opposite conclusion: small residues $(0.06 \mathrm{~cm}$ long $)$ showed much greater mineralization than residues more than $0.5 \mathrm{~cm}$ long. These authors consider the determining factor to be the potential contact surface of these residues with the soil, as smaller vegetal residues appear to have a larger contact surface. During the first hundred time-steps of the simulation with MIOR, results also showed greater mineralization for the smallest OMsphere objects (Control). It would be of interest to extend the incubation times to see whether the mineralization of relatively larger residues increased in the long term, as would appear to be confirmed by the work of Angers \& Recous (1997).

\section{Conclusion}

The results obtained using the MIOR model show that the number of contacts between microbial communities and their substrate determine the dynamics of the decomposers and the dynamics of the substrate decomposition products. This parameter will naturally be a function of the specific surface of a residue and the size of the microbial activity spots as well as their relative distribution in space. The model highlights the effect of the number of microorganisms that do not have access to any organic resource on the microbial activity in a soil.

The model can incorporate other parameters such as the distribution in the simulated space of an exogenous source of mineral nitrogen. It is envisaged being able to simulate levels of organization such as soil structure. Research is currently being carried out on these points.

\section{Acknowledgements}


This work received the financial support from the PNSE-2002 French program. Special thanks to Alioun Badara and Mahamadou Belem from the University of Bobo Dioulasso for the computer program conception, and, to the anonymous reviewers who helped us to improve this work. 


\section{References}

Ågren, G.I. \& Bosatta, E. 1996. Quality: a bridge between theory and experiment in soil organic matter studies. OIKOS, 76, 522-528.

Angers, D.A. \& Recous, S. 1997. Decomposition of wheat straw and rye residues as affected by particle size. Plant and Soil, 189, 197-203.

Bending, G.D. \& Turner, M.K. 1999. Interaction of biochemical quality and particle size of crop residues and its effect on the microbial biomass and nitrogen dynamics following incorporation into soil. Biology and Fertility of Soils, 29, 319-327.

Blagodatsky, S.A. \& Richter, O. 1998. Microbial growth in soil and nitrogen turnover: a theoretical model considering the activity state of microorganisms. Soil Biology and Biochemistry, 30, 1743-1755.

Bousquet, F. \& Le Page, C. 2004. Multi-agent simulations and ecosystem management: a review. Ecological Modelling, 176, 313-332.

Chenu, C. \& Stotzky, G. 2002. Interactions between microorganisms and soil particles: an overview. In: Interactions between Soil Particles and Microorganisms (eds P.M. Huang, J.-M. Bollag \& N. Senesi), pp. 3-40. Wiley, New York.

Chotte, J.L., Ladd, J.N. \& Amato, M. 1997. Sites of microbial assimilation, and turnover of soluble and particulate 14C-labelled substrates decomposing in a clay soil. Soil Biology and Biochemistry, 30, 205-218.

Christensen, B.T. 1996. Matching measurable soil organic matter fractions with coneptual pools in simulation models of carbon turnover: Revision of model structure. In: Evaluation of soil organic matter models (eds D.S. Powlson, P. Smith \& J.U. Smith), pp. 143-160. Springer Verlag, Berlin Heidelberg.

Ettema, C.H. \& Wardle, D.A. 2002. Spatial soil ecology. Trends in Ecology \& Evolution, 17, $177-183$ 
Feller, C. \& Beare, M.H. 1997. Physical control of soil organic matter dynamics in the tropics. Geoderma, 79, 69-116.

Gaillard, V., Chenu, C. \& Recous, S. 2003. Carbon mineralisation in soil adjacent to plant residues of contrasting biochemical quality. Soil Biology and Biochemistry, 35, 93-99.

Garnier, P., Néel, C., Aitac, C., Recous, S., Lafolie, F. \& Mary, B. 2003. Modelling carbon and nitrogen dynamics in a bare soil with and without straw incorporation. European Journal of Soil Science, 54, 555-568.

Gignoux, J., House, J., Hall, D., Masse, D., Nacro, H.B. \& Abbadie, L. 2001. Design and test of a generic cohort model of soil organic matter decomposition: the SOMKO model. Global Ecology \& Biogeography, 10, 639-660.

Ginot, V., Le Page, C. \& Souissi, S. 2002. A multi-agents architecture to enhance end-user individual-based modelling. Ecological Modelling, 157, 23-41.

Grundmann, G.L. \& Debouzie, D. 2000. Geostatistical analysis of the distribution of NH4+ and NO2--oxidizing bacteria and serotypes at the millimeter scale along a soil transect. FEMS Microbiology Ecology, 34, 57-62.

Grundmann, G.L., Dechesne, A., Bartoli, F., Flandrois, J.P., Chasse, J.L. \& Kizungu, R. 2001. Spatial modeling of nitrifier microhabitats in soil. Soil Science Society of America Journal, 65, 1709-1716.

Kreft, J.-U., Booth, G. \& Wimpenny, J.W.T. 1998. BacSim, a simulator for individual-based modelling of bacterial colony growth. Microbiology-UK, 144, 3275-3287.

McGill, W.B. 1996. Review and classification of ten soil organic matter (SOM) models. In: Evaluation of soil organic matter models (eds D.S. Powlson, P. Smith \& J.U. Smith), pp. 111-132. Springer-Verlag, Berlin Heidelberg.

Minderman, G. 1968. Addition, decomposition and accumulation of organic matter in forests. Journal of Ecology, 56, 355-362. 
Nunan, N., Ritz, K., Crabb, D., Harris, K., Wu, K., Crawford, J.W. \& Young, I.M. 2001. Quantification of the in situ distribution of soil bacteria by large-scale imaging of thin sections of undisturbed soil. FEMS Microbiology Ecology, 37, 67-77.

Nunan, N., Wu, K., Young, I.M., Crawford, J.W. \& Ritz, K. 2002. In situ spatial patterns of soil bacterial populations, mapped at multiple scales, in an arable soil. Microbial Ecology.

Paul, E.A. \& Clark, F.E. 1996. Soil Microbiology and Biochemistry. Academic Press, San Diego, USA.

Peck, S.L. 2004. Simulation as experiment: a philosophical reassessment for biological modeling. Trends in Ecology \& Evolution, 19, 530-534.

Ranjard, L., Brothier, E. \& Nazaret, S. 2000. Sequencing bands os ribosomal intergenic spacer analysis fingerprints for characterization and microscale distribution of soil bacterium populations responding to mercury spiking. Applied and Environmental Microbiology, 66, 5334-5339.

Six, J., Bossuyt, H., Degryze, S. \& Denef, K. 2004. A history of research on the link between (micro)aggregates, soil biota, and soil organic matter dynamics. Soil and Tillage Research, 79, 7-31.

Six, J., Elliott, E.T. \& Paustian, K. 2000. Soil macroaggregate turnover and microaggregate formation: a mechanism for $\mathrm{C}$ sequestration under no-tillage agriculture. Soil Biology and Biochemistry, 32, 2099-2103.

Tisdall, J.M. \& Oades, J.M. 1982. Organic matter and water-stable aggregates in soils. Journal of Soil Science, 33, 141-163.

Trinsoutrot, I., Recous, S., Bentz, B., Lineres, M., Cheneby, D. \& Nicolardot, B. 2000. Biochemical quality of crop residues and carbon and nitrogen mineralization kinetics under nonlimiting nitrogen conditions. Soil Science Society of America Journal, 64, 918-926. 
Vargas, R. \& Hattori, T. 1986. Protozoan predation of bacterial cells in soil aggregates. FEMS Microbial Ecology, 38, 233-242.

Vieublé-Gonod, L., Chenu, C. \& Soulas, G. 2003. Spatial variability of 2,4dichlorophenoxyacetic acid (2,4-D) mineralisation potential at a millimetre scale in soil. Soil Biology and Biochemistry, 35, 373-382.

Wachinger, G., Fiedler, S., Zepp, K., Gattinger, A., Sommer, M. \& Roth, K. 2000. Variability of soil methane production on the micro-scale: spatial association with hot spots of organic material and Archaeal populations. Soil Biology and Biochemistry, 32, 1121-1130.

Young, I.M. \& Crawford, J.W. 2004. Interactions and self-organization in the soil-microbe complex. Science, 304, 1634-1637. 


\section{FIGURE CAPTIONS}

Figure 1 MIOR individual-based model. Random distribution in space of objects assumed to be spheres and which represent the microorganisms MetaMior (light grey) and the organic matter $O M$ (mid-grey). The distance between the centres of two spheres compared with the sum of the radii of these spheres is used to determine the accessibility of a MetaMior to organic matter.

Figure 2 Theoretical representation of the scenarios simulated. Based on a random distribution (control) of two sets of objects, the MetaMior (white) and the organic matter (black), the objects are regrouped in heaps at two degrees of clustering: S- small and L- large. Scenario 1 clusters the MetaMior (on the left, S-MM and L- $M M$ ) and scenario 2 clusters the $O M$ (on the right, S-OM and L-OM).

Figure 3 Number of MetaMior (as a proportion of the total number of MetaMior) classified by the ratio $O M-\mathrm{C}_{\text {accessible }}: M M-\mathrm{C}_{\text {content }}$ for $\mathrm{A}$ ) scenario 1 (MetaMior degree of clustering, $\mathrm{S}$ MM, L-MM), for B) scenario 2 ( $O M$ degree of clustering, S-OM, L-OM) compared in each case with the distribution without clustering (control).

Figure 4 Change in the microbial biomass of a MetaMior $\left(M M-\mathrm{C}_{\text {content }}\right)$ expressed with respect to the initial quantity $\left(M M-\mathrm{C}_{\mathrm{to}}\right)$ as a function of time for the values in ratio $O M-$ $\mathrm{C}_{\text {accessible }}: M M-\mathrm{C}_{\text {content }}$ from 0 to 1600 .

Figure 5 Change in the microbial biomass $M B-C$ (expressed with respect to the total initial $M B-\mathrm{C}: M B-\mathrm{C}_{\mathrm{to}}$ ) over time for scenarios $1(\mathrm{~A})$ and $2(\mathrm{~B})$ and the different degrees of clustering of MetaMior (S-MM and L-MM) and OMs (S-OM and L-OM) compared with the distribution without clustering (control). The bars represent the standard error $(\mathrm{n}=5)$.

Figure 6 Change in $\mathrm{CO} 2-\mathrm{C}$ release over time for scenarios 1 (A) clustering of MetaMior and 2 (B) clustering of OM, and the different degrees of clustering of MetaMior (S-MM and L$\mathrm{MM}$ ) and OM (S-OM and L-OM) compared with the distribution without clustering (control). 


\section{TABLES}

Table 1 Initial parameters used to simulate two degrees (small and large) of clustering scenarios of the microorganisms (MetaMior) and the organic matter $(\mathrm{OM})$ in soil.

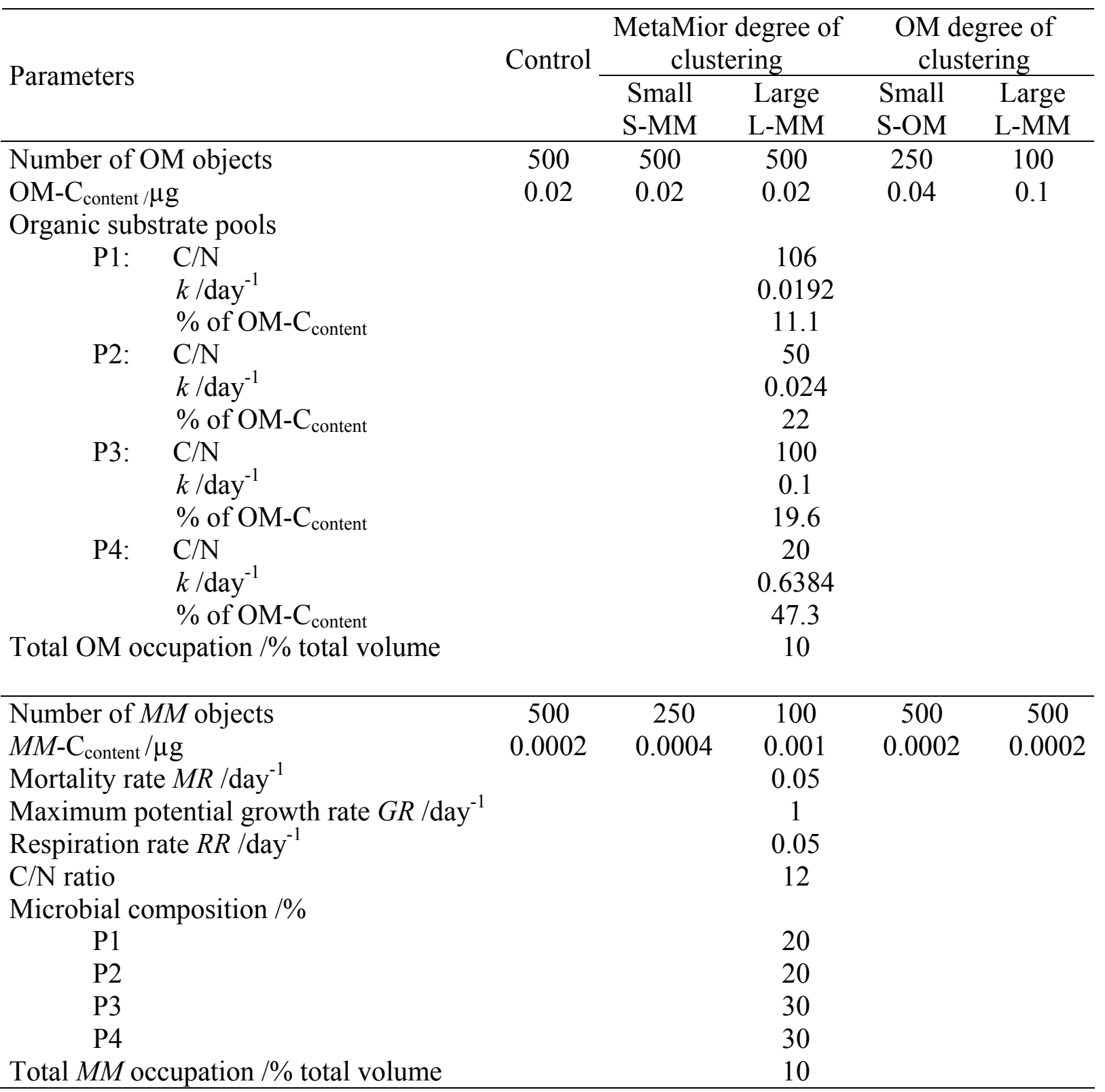



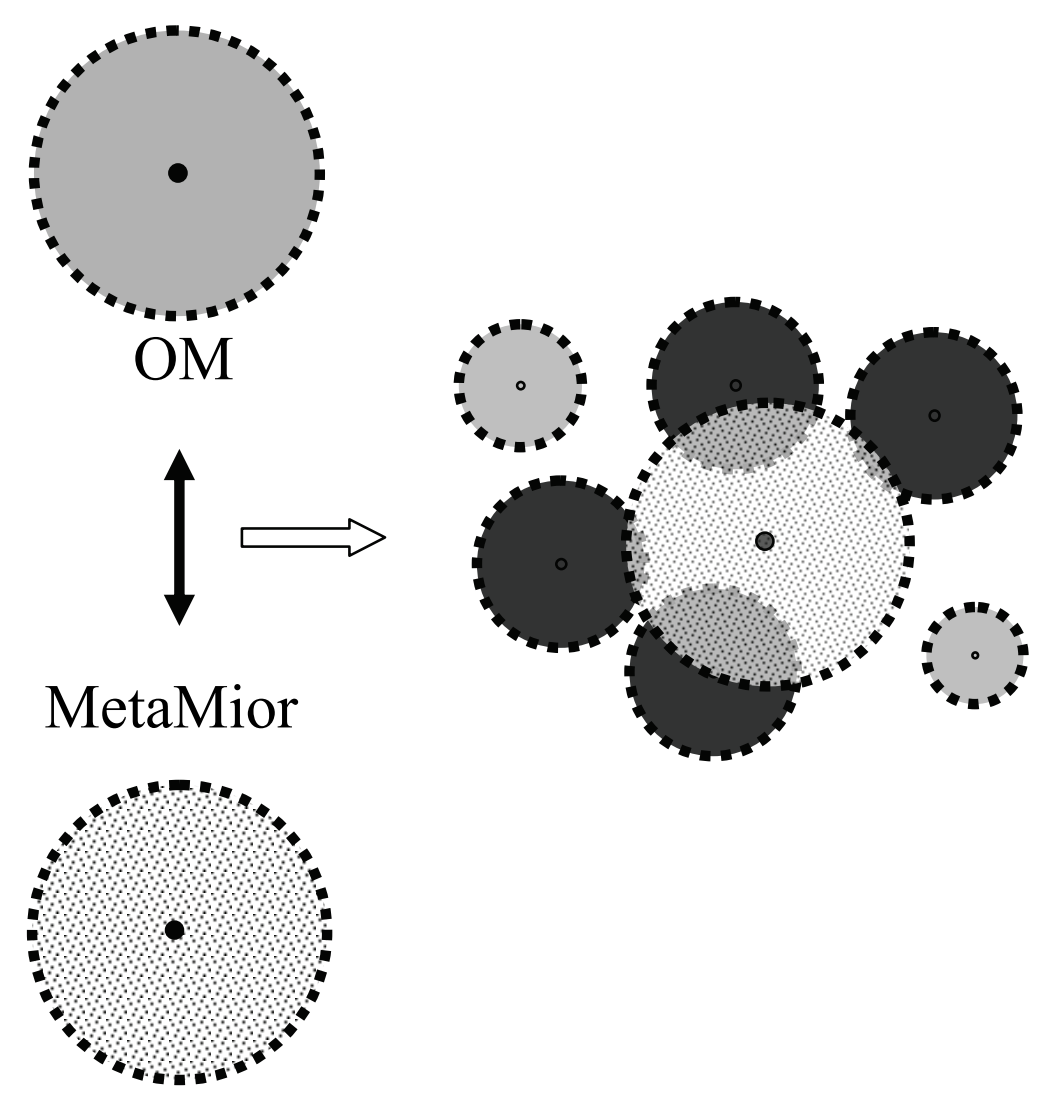

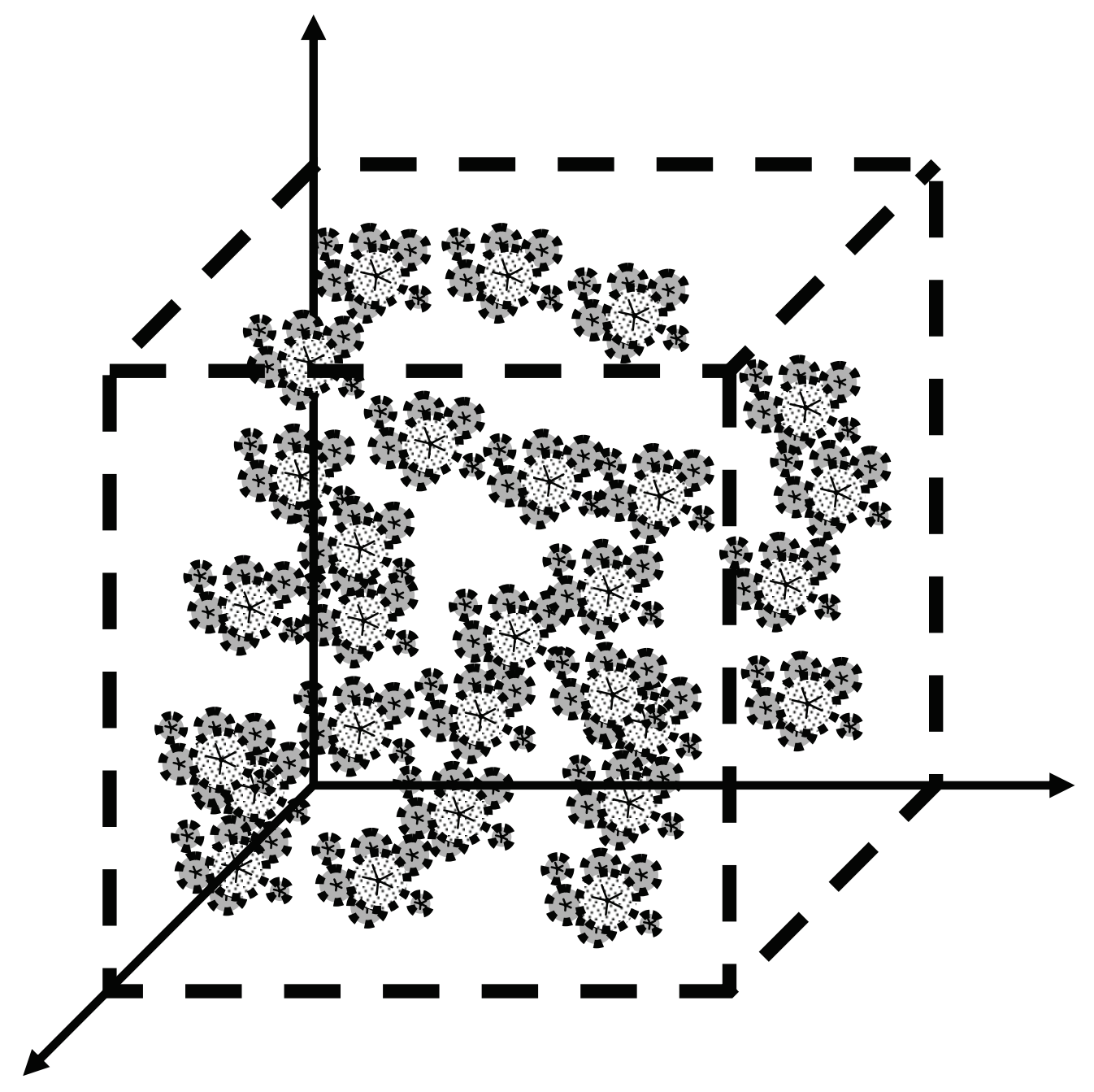

Figure 1 
Degree of clustering of MetaMior

Small degree of clustering $(S-M M)$

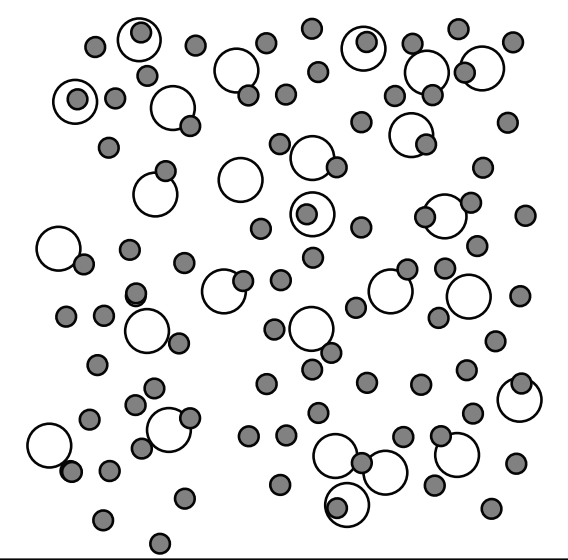

Large degree of clustering $(L-M M)$

$$
\begin{aligned}
& a_{0}^{0} 0 \int_{0}^{0} 0 \int_{0}^{0}
\end{aligned}
$$

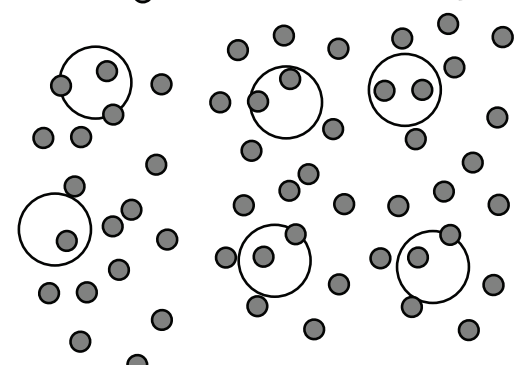

Figure 2
Degree of clustering of $O M$

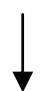

Small degree of clustering $(S-O M)$

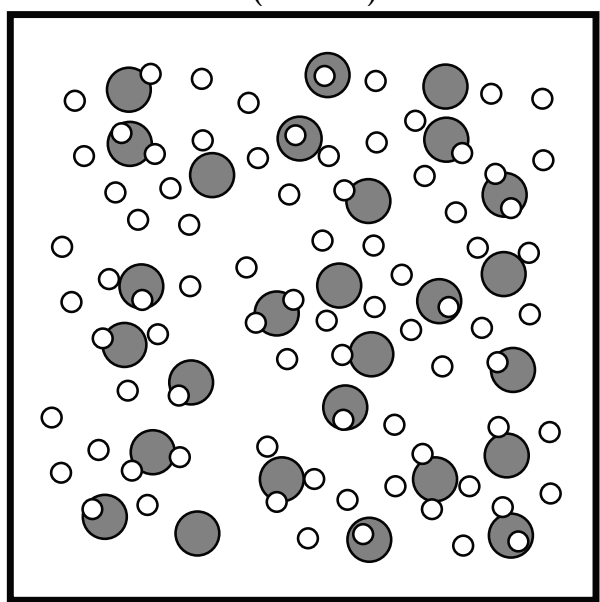

Large degree of clustering

$$
(L-O M)
$$

$$
\begin{aligned}
& \overbrace{0}^{0} 0_{0}^{0} 0 \int_{0}^{0} 0_{0}^{0} 0_{0}^{0} \int_{0}^{0} \\
& \underbrace{0}_{0} 0_{0}^{0} \int_{0}^{0} \int_{0}^{0} \int_{0}^{0}
\end{aligned}
$$

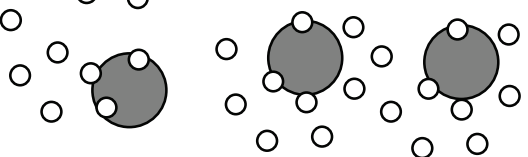




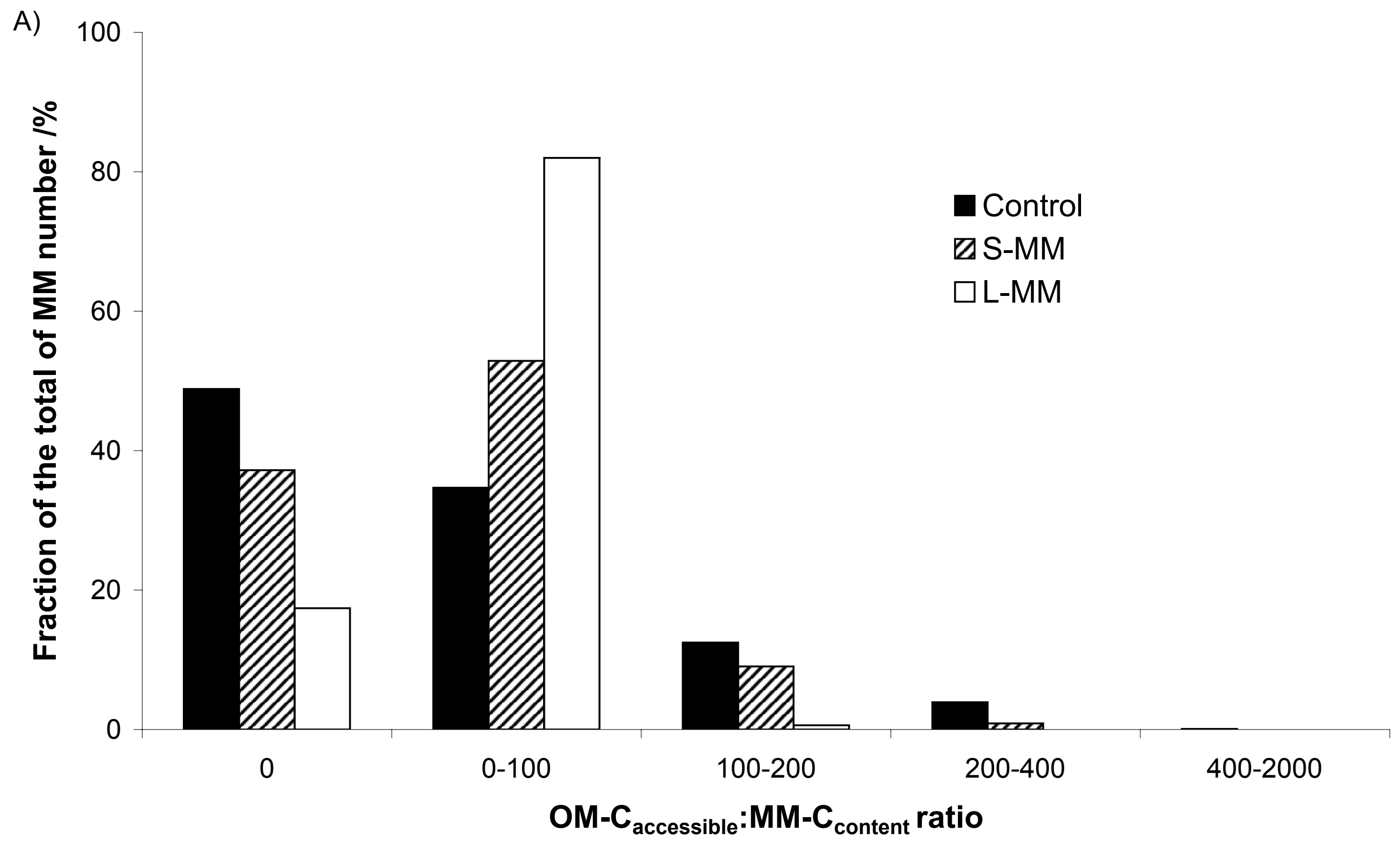




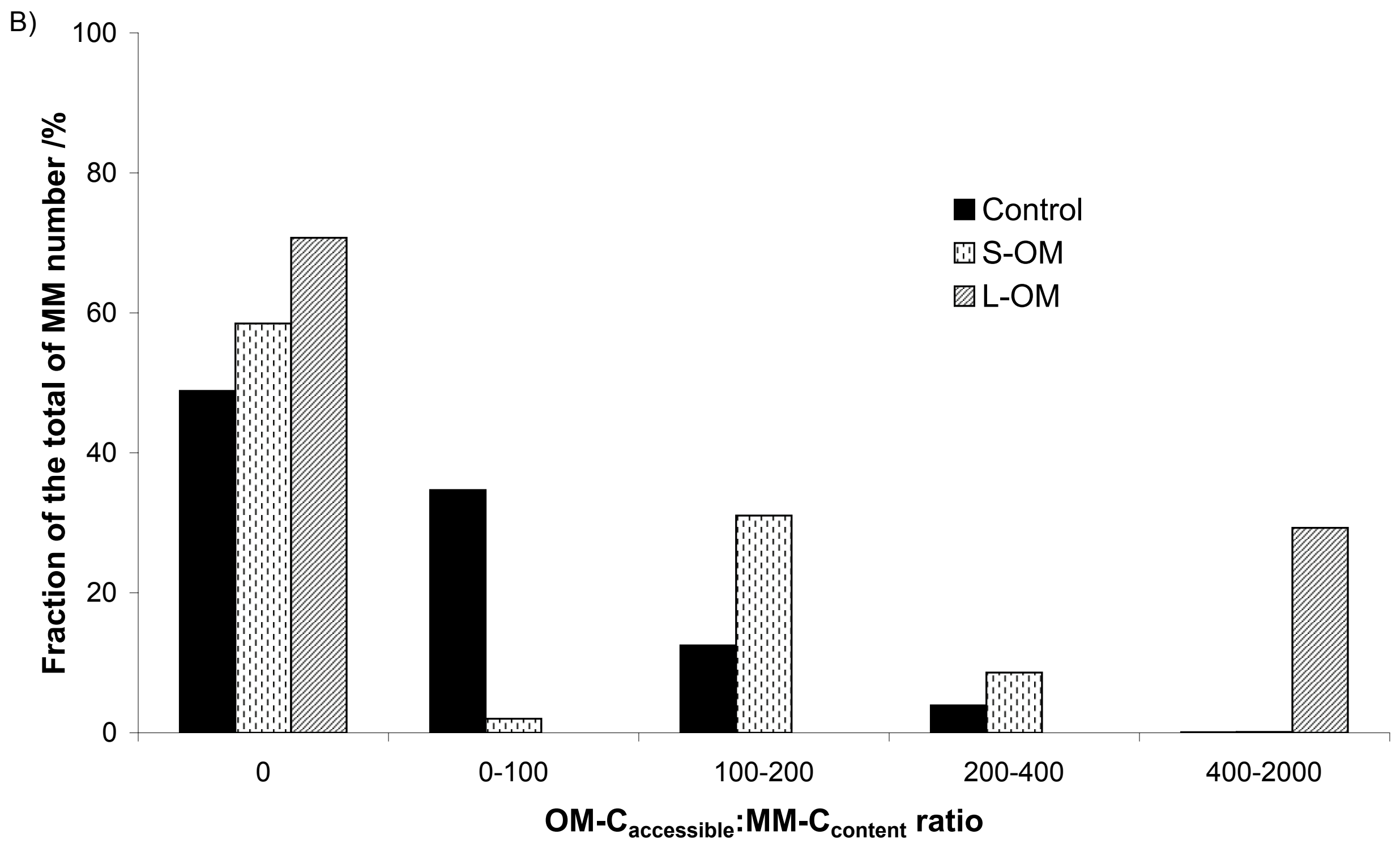




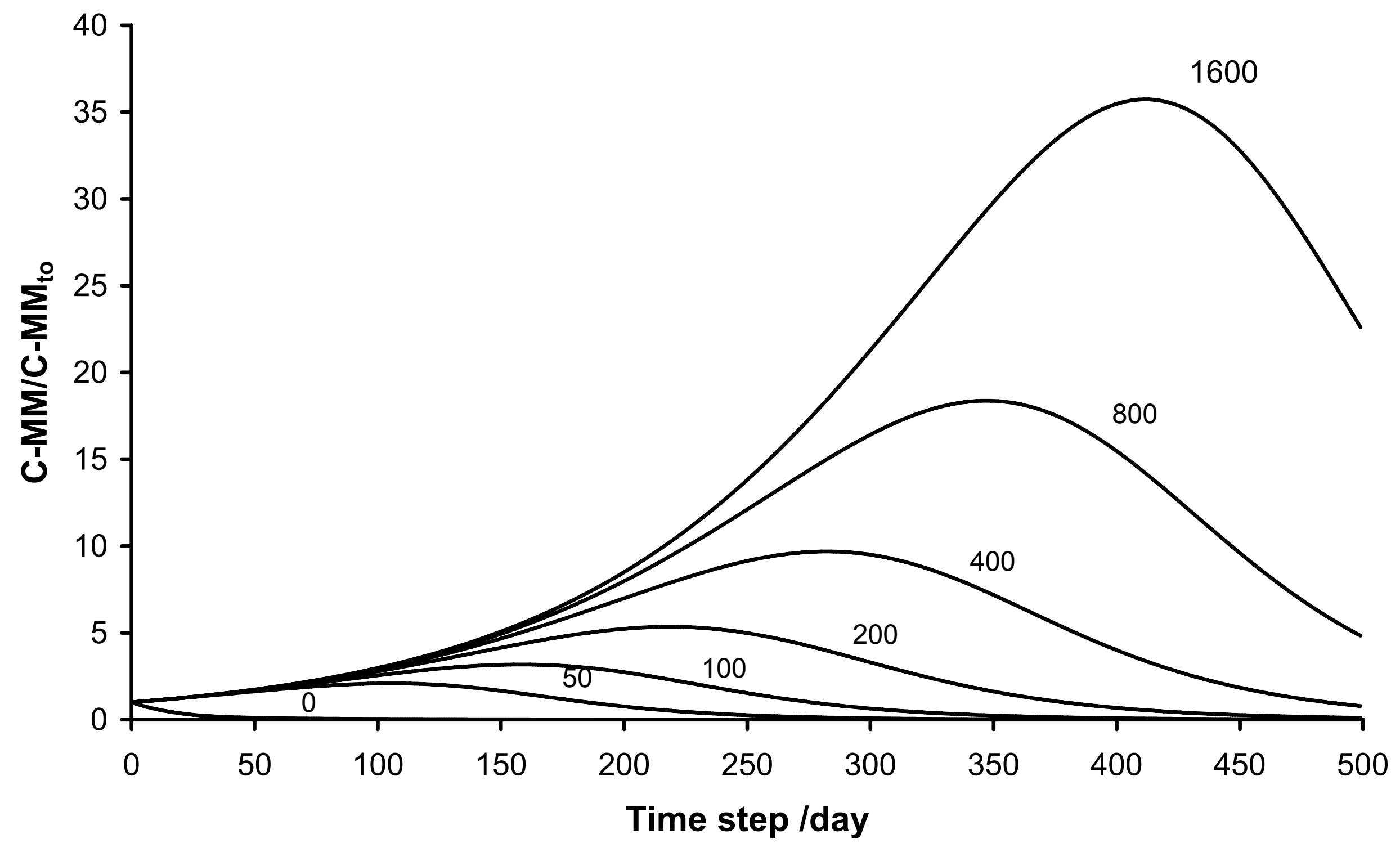



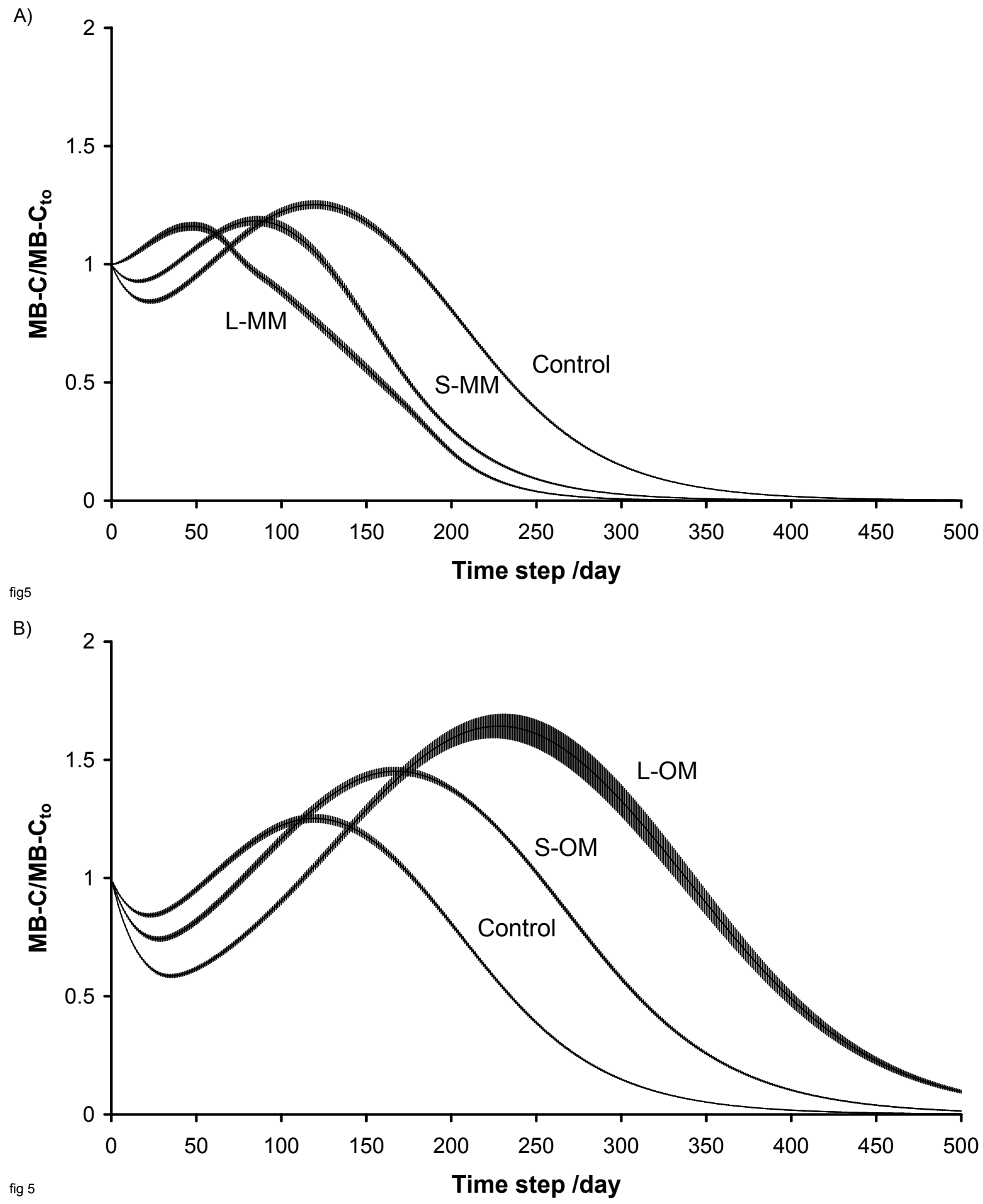

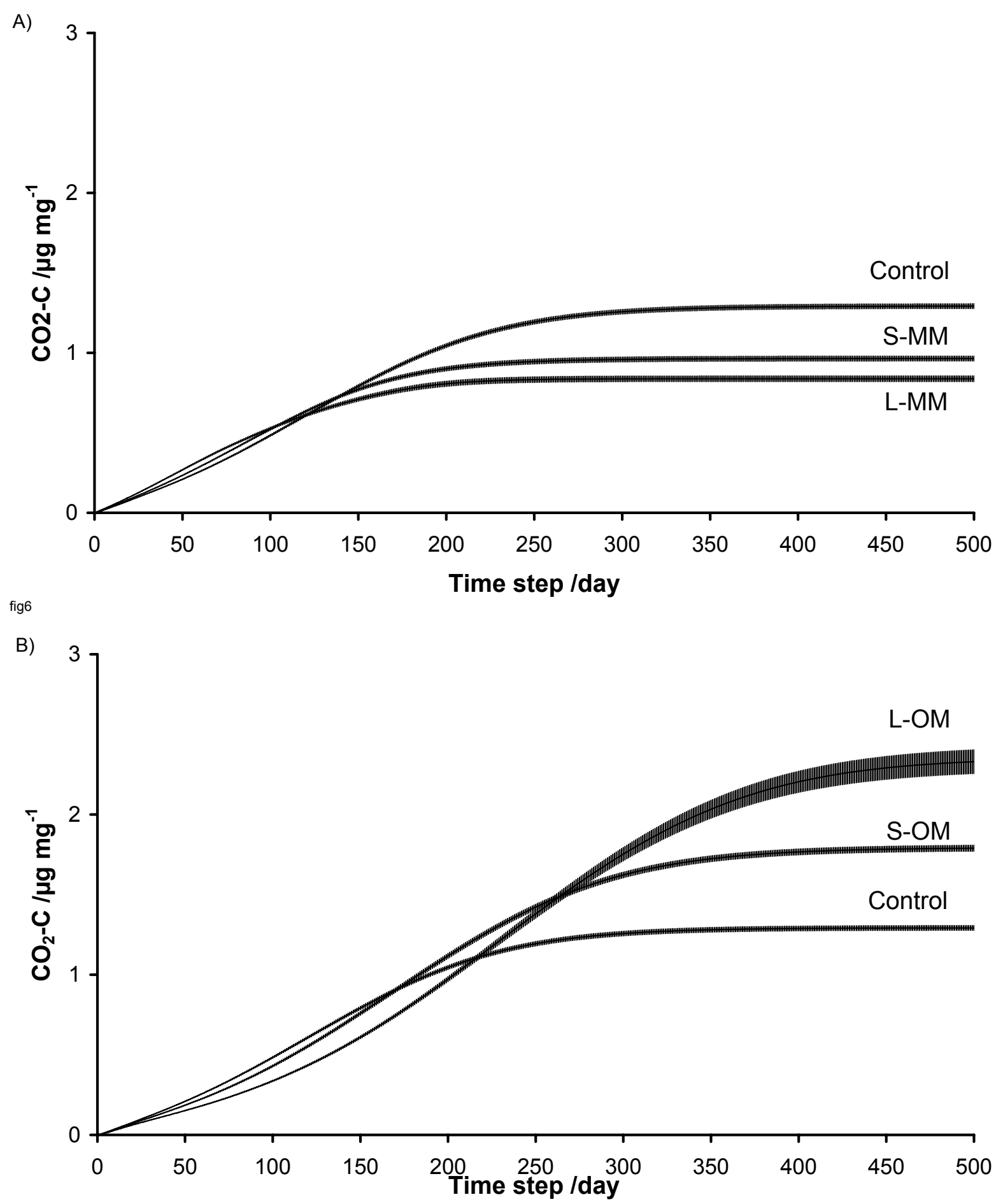